\title{
Risk Factors and Co-Existence of Infectious Causes of Reproductive Failures in Selected Uganda Cattle and Goats: A Brucella spps-Toxoplasma gondii Study
}

\author{
Steven Kakooza ${ }^{1}$, Maria Tumwebaze ${ }^{1}$, Esther Nabatta ${ }^{1}$, Joseph Byaruhanga1, \\ Dickson Stuart Tayebwa1, Edward Wampande ${ }^{1,2}$ \\ ${ }^{1}$ Central Diagnostic Laboratory, College of Veterinary Medicine, Animal Resources and Bio-Security, Makerere University, \\ Kampala, Uganda \\ ${ }^{2}$ Department of Veterinary Pharmacy, Clinics and Comparative Medicine, College of Veterinary Medicine, Animal Resources and \\ Bio-Security, Makerere University, Kampala, Uganda \\ Email: *ksteven310@gmail.com
}

How to cite this paper: Kakooza, S., Tumwebaze, M., Nabatta, E., Byaruhanga, J., Tayebwa, D.S. and Wampande, E. (2018) Risk Factors and Co-Existence of Infectious Causes of Reproductive Failures in Selected Uganda Cattle and Goats: A Brucella sppsToxoplasma gondii Study. Open Access Library Journal, 5: e4502.

https://doi.org/10.4236/oalib.1104502

Received: March 13, 2018

Accepted: April 21, 2018

Published: April 24, 2018

Copyright (๑) 2018 by authors and Open Access Library Inc.

This work is licensed under the Creative Commons Attribution International License (CC BY 4.0).

http://creativecommons.org/licenses/by/4.0/

\begin{abstract}
Reproductive diseases are one of the most significant challenges in livestock breeding and production. The present study was done to determine the 1) sero-prevalence of Brucella spps and Toxoplasma gondii in bovine and caprine samples, 2) risk factors associated with sero-positivity, 3) occurrence of Brucella- $T$. gondii co-existence with emphasis on samples with a history of reproductive failure. To fulfill the stated objectives, a retrospective study was carried out in May, 2015 on livestock blood samples received by Central Diagnostic Laboratory for the period of February, 2014 to January, 2015. A total of 279 serum samples from livestock were submitted by farmers and veterinary practitioners for serological diagnostic tests. Of the total (279), 59 blood samples had sufficient bio-data crucial for their inclusion in the study and were screened for antibodies against Brucella spps using Standard Rose Bengal Antigen. Toxoplasma gondii infection was also confirmed by using multi species indirect ELISA Test kit. The overall Brucella and $T$. gondii serological prevalence derived from the samples was $49.2 \%$ and $3.4 \%$ respectively. A significant association was found between animal species $\left(\mathrm{X}^{2}=3.836, P=0.049\right)$, breed $\left(\mathrm{X}^{2}=0.279, P=0.041\right)$ and occurrence of Brucellosis. An overall prevalence of 3.8\% mixed infection to Brucella spps and T. gondii in bovine samples was obtained where 2 animals which had previous occurrence of abortion were found positive. Information obtained from the study will add on already existing one in attempt to build a fulcrum for taming livestock reproductive failures a step to boosting productivity.
\end{abstract}




\section{Subject Areas}

Veterinary Medicine

\section{Keywords}

Reproductive Diseases, Abortion, Still Birth, Brucella spps and Toxoplasma gondii Prevalence, Uganda

\section{Introduction}

Reproductive diseases are one of the most significant challenges in livestock breeding and production where their aftermaths of occurrence have been associated with reproductive losses such as early embryonic losses, abortion, still birth and mummifications. The latter have caused great economic losses felt in terms of culling, increased treatment and preventative measurement costs [1] [2]. Abortions and still births are one of the commonest failures and may result from a broad range of causes which maybe idiopathic, metabolic or hormonal abnormalities related, nutritional deficiencies, trauma, toxicities and infectious causes [3]. The spectrum of infectious causes of abortion and still birth includes bacterial, viral, protozoan and fungal agents [4]. Among the bacterial infectious diseases, Brucellosis has proved to be a burden in different breeding and milk production systems. The disease is highly contagious and an important zoonotic caused by various species of the genus Brucella thus their presence in animals and their products can be fatal in terms of animal herd fertility issues and also pose significant human health risk [5] [6] [7]. Protozoan parasites are also a significant cause of infertility in domestic ruminants. The occurrence of two-host life cycle oriented protozoan parasites: Toxoplasma gondii, Neospora caninum and Sarcocystis species in farm animals has also aggravated infertility issues in livestock [8]. Over the years, researchers have gained interest in $T$. gondii herd prevalences and its role in etiology of abortion and other fertility failures. $T$. gondii is among the most prevalent parasitic diseases of humans and animals worldwide [9]. Manifestation in many species is usually subclinical but the effects of infection can manifest as mental retardation, blindness, abortion or congenital birth defects [10]. Past and recent brucellosis studies done in Uganda and also globally have dwelt much on its prevalence and risk factors for positivity in farm produce animals [11] [12] [13] [14]. Global research based information on $T$. gondii has centered on herd prevalences in various animal species and quite a number of studies have been done in other countries [15] [16] [17] [18] [19]. In Uganda, major findings on $T$. gondii by Lindström et al., 2006, Lindström et al., 2008 do not show its occurrence and role in cattle and goats since they were done on human and avian species thus potentiating need for investigating outcomes of its manifestation in cattle and goats. Currently only one study on T. gondii in Ugandan goats by researchers Bisson et al., 2000 has estab- 
lished only its prevalence thus need for more resourceful information. In addition, there is no evidence regarding risk factors potentiating $T$. gondii infection in animals and also the possibility of co-existence of Brucella spps and T. gondii infection a tool that can be embraced for in depth diagnosis of etiology of reproductive failures in animals. From the current situation, we probed to investigate and compare the prevalence of Brucella spps and T. gondii in Bovines and Caprines from Uganda with the prevalences from other countries. Risk factors for Brucella spps and T. gondii sero-positivity in Ugandan animals were also assessed in attempt to compare with existing findings and also fill the gap of sparse information on $T$. gondii. The study also analyzed the possibility of occurrence of mixed infection of Brucellosis and Toxoplasmosis in Ugandan cattle and goats especially those with history of reproductive failures.

\section{Methods and Materials}

\subsection{Study Design, Area, and Sample Size}

A retrospective study was carried out in May, 2015 on livestock blood samples received by Central Diagnostic Laboratory, College of Veterinary medicine Animal resources and Bio-security Makerere University during the period of February, 2014 to January, 2015 for diagnostic tests from Central and Western Uganda. Of the total (279), 59 blood samples had sufficient bio-data crucial for their inclusion in the study. The inclusion criteria were based on the following: complete bio-data, blood in proper sample container for serological tests, only caprine and bovine samples were included. The 59 sera samples which had been storedin sterile Cryo vials at $-20^{\circ} \mathrm{C}$ were thawed prior serological detection of antibodies against $T$. gondii and Brucella spps. Basic biological data on cows and nannies such as breed, sex, age, region of sample origin, clinical history were obtained from laboratory records taken from sample submitter.

\subsection{Detection of Antibodies against T. gondii Using ELISA}

Samples were tested for antibodies as a result of Toxoplasma gondii infection by ELISA using the multi-species ID Screen Toxoplasmosis Indirect commercial kit (IDVET, Germany). Basing on the manufacturer's guide, samples with S/P values greater or equal to $50 \%$ were considered positive, between $40 \%$ and $50 \%$ were doubtful, while those having values less than or equal to $40 \%$ were considered negative [20]. As per the study scope, only positive cases were recorded and the doubtful ones left out.

\subsection{Detection of Antibodies against Brucella spps Using Rose Bengal Antigen}

Screening of antibodies against Brucella spps was done using standard Rose Bengal agglutination test. The positive bovine samples were confirmed by agglutination upon mixing of $30 \mu \mathrm{l}$ of Antigen with an equal volume of serum on a white tile. Modified Rose Bengal Test was used for the caprine samples which 
involved mixing of $30 \mu \mathrm{l}$ of Antigen and $90 \mu \mathrm{l}$ of caprine serum on a white tile. For both tests, results were considered valid within 4 minutes [21].

\subsection{Statistical Analysis}

The raw data was processed by Microsoft Excel and analyzed by SPSS [Statistical Analysis System, Version 16, Chicago, Illinois, USA]. The Pearson's chi-squared test $\left[\mathrm{X}^{2}\right]$ was done to find differences in prevalences among categorical variables of animal parameters of species, breed, region of origin, history and past frequency of reproductive failureat a 95\% confidence interval. Animal Parameters with $\mathrm{P}$-values less or equal to 0.05 were considered statistically significant thus were taken as probable risk factors linked with sero-positivity [22].

\section{Results}

The results below reflect overall prevalence and sero-prevalence in relation to different risk parameters at individual animal level. Table 1 and Table 2 summarize the analysis of risk factors for Brucella spps and T. gondii sero-positivity respectively. Table 3 shows the occurrence of Brucella spps and T. gondii mixed infection in relation to different parameters.

The prevalences of Brucella spps and T. gondii in the 59 submitted samples were $49.2 \%$ (29) and $3.4 \%$ (2) respectively.

Table 1. Brucella spps sero-prevalence and associated risk factors.

\begin{tabular}{|c|c|c|c|c|}
\hline \multirow{2}{*}{ Variable } & \multirow{2}{*}{ Category } & \multicolumn{2}{|c|}{ Brucella spps } & \multirow{2}{*}{$P$-value } \\
\hline & & Cases N (\%) & Sero-positivity N (\%) & \\
\hline \multirow{2}{*}{ Animal Species* } & Bovine & $52(88.1)$ & $28(53.8)$ & \multirow{2}{*}{0.049} \\
\hline & Caprine & $7(11.9)$ & $1(14.3)$ & \\
\hline \multirow{3}{*}{ Animal Breed ${ }^{*}$} & Local & $15(25.4)$ & $6(40)$ & \multirow{3}{*}{0.041} \\
\hline & Exotic & $25(42.4)$ & $17(68)$ & \\
\hline & Cross & $19(32.2)$ & $6(31.6)$ & \\
\hline \multirow[b]{2}{*}{ Region of origin } & Central Uganda & $25(42.4)$ & $15(60)$ & \multirow{2}{*}{0.153} \\
\hline & Western Uganda & $34(57.6)$ & $14(41.2)$ & \\
\hline \multirow{3}{*}{$\begin{array}{l}\text { History of reproductive } \\
\text { failure }\end{array}$} & Abortion & $46(78)$ & $22(47.8)$ & \multirow{3}{*}{0.586} \\
\hline & Still birth & $1(1.7)$ & $1(100)$ & \\
\hline & No failure & $12(20.3)$ & $6(50)$ & \\
\hline \multirow{3}{*}{$\begin{array}{l}\text { Past frequency of } \\
\text { Abortion }\end{array}$} & Four & $17(28.8)$ & $12(70.6)$ & \multirow{3}{*}{0.102} \\
\hline & One & $23(39)$ & $10(43.5)$ & \\
\hline & Zero & $19(32.2)$ & $7(36.8)$ & \\
\hline \multirow{2}{*}{$\begin{array}{l}\text { Past frequency of Still } \\
\text { birth }\end{array}$} & One & $1(1.7)$ & $1(100)$ & \multirow{2}{*}{0.305} \\
\hline & Zero & $58(98.3)$ & $28(48.3)$ & \\
\hline
\end{tabular}

${ }^{\star}$ Factors associated with sero-positivity at $5 \%$ significance level $(P<0.05)$. 
Table 2. Toxoplasma gondii sero-prevalence and associated risk factors.

\begin{tabular}{|c|c|c|c|c|}
\hline \multirow{2}{*}{ Variable } & \multirow{2}{*}{ Category } & \multicolumn{2}{|c|}{ Toxoplasma gondii } & \multirow{2}{*}{$P$-value } \\
\hline & & Cases N (\%) & Sero-positivity N (\%) & \\
\hline \multirow{2}{*}{ Animal Species } & Bovine & $52(88.1)$ & $2(3.8)$ & \multirow{2}{*}{0.598} \\
\hline & Caprine & $7(11.9)$ & $0(0)$ & \\
\hline \multirow{3}{*}{ Animal Breed } & Local & $15(25.4)$ & $0(0)$ & \multirow{3}{*}{0.245} \\
\hline & Exotic & $25(42.4)$ & $2(8)$ & \\
\hline & Cross & $19(32.2)$ & $0(0)$ & \\
\hline \multirow{2}{*}{ Region of origin } & Central & $25(42.4)$ & $1(4)$ & \multirow{2}{*}{0.824} \\
\hline & Western & $34(57.6)$ & $1(2.9)$ & \\
\hline \multirow{3}{*}{$\begin{array}{l}\text { History of } \\
\text { reproductive failure }\end{array}$} & Abortion & $46(78)$ & $2(4.3)$ & \multirow{3}{*}{0.746} \\
\hline & Still birth & $1(1.7)$ & $0(0)$ & \\
\hline & No failures & $12(20.3)$ & $0(0)$ & \\
\hline \multirow{3}{*}{$\begin{array}{l}\text { Past frequency of } \\
\text { Abortion }\end{array}$} & Four & $17(28.8)$ & $1(5.9)$ & \multirow{3}{*}{0.590} \\
\hline & One & $23(39)$ & $1(4.3)$ & \\
\hline & Zero & $19(32.2)$ & $0(0)$ & \\
\hline \multirow{2}{*}{$\begin{array}{l}\text { Past frequency of Still } \\
\text { birth }\end{array}$} & One & $1(1.7)$ & $0(0)$ & \multirow{2}{*}{0.850} \\
\hline & Zero & $58(98.3)$ & $2(3.4)$ & \\
\hline
\end{tabular}

${ }^{\star}$ Factors associated with sero-positivity at 5\% significance level $(P<0.05)$

Table 3. Occurrence of brucella spps and $T$. gondii mixed infection.

\begin{tabular}{|c|c|c|c|c|}
\hline \multirow{2}{*}{ Variable } & \multirow{2}{*}{ Category } & \multicolumn{2}{|c|}{ Brucella-T. gondii mixed infection } & \multirow{2}{*}{$P$-value } \\
\hline & & Cases N (\%) & Sero-positivity N (\%) & \\
\hline \multirow{2}{*}{ Animal Species } & Bovine & $52(88.1)$ & $2(3.8)$ & \multirow{2}{*}{0.598} \\
\hline & Caprine & $7(11.9)$ & $0(0)$ & \\
\hline \multirow{3}{*}{ Animal Breed } & Local & $15(25.4)$ & $0(0)$ & \multirow{3}{*}{0.245} \\
\hline & Exotic & $25(42.4)$ & $2(8)$ & \\
\hline & Cross & $19(32.2)$ & $0(0)$ & \\
\hline \multirow{2}{*}{ Region of origin } & Central & $25(42.4)$ & $1(4)$ & \multirow{2}{*}{0.824} \\
\hline & Western & $34(57.6)$ & $1(2.9)$ & \\
\hline \multirow{3}{*}{$\begin{array}{l}\text { History of } \\
\text { reproductive failure }\end{array}$} & Abortion & $46(78)$ & $2(4.3)$ & \multirow{3}{*}{0.746} \\
\hline & Still birth & $1(1.7)$ & $0(0)$ & \\
\hline & No failures & $12(20.3)$ & $0(0)$ & \\
\hline \multirow{3}{*}{$\begin{array}{l}\text { Past frequency of } \\
\text { Abortion }\end{array}$} & Four & $17(28.8)$ & $1(5.9)$ & \multirow{3}{*}{0.590} \\
\hline & One & $23(39)$ & $1(4.3)$ & \\
\hline & Zero & $19(32.2)$ & $0(0)$ & \\
\hline \multirow{2}{*}{$\begin{array}{l}\text { Past frequency of } \\
\text { Still birth }\end{array}$} & One & $1(1.7)$ & $0(0)$ & \multirow{2}{*}{0.850} \\
\hline & Zero & $58(98.3)$ & $2(3.4)$ & \\
\hline
\end{tabular}

\subsection{Sero-Prevalence in Relation to Animal Species}

Antibodies against Brucella spps were detected in 53.8\% (28) of the bovine sam- 
ples and 14.3\% (1) of the caprine samples. Both species groups had positive cases for Brucella spps antibodies. A significant difference in Brucella sero prevalence between both groups was confirmed $\left(\mathrm{X}^{2}=3.836, P=0.049\right)$. Antibodies against T. gondii at species level were detected in $2(3.8 \%)$ bovine samples and in none (0\%) of the caprine samples. There was no significant difference in $T$. gondii antibody sero prevalence between the samples of caprine and bovine origin $\left(\mathrm{X}^{2}=\right.$ $0.279, P=0.598)$. Positive cases were only found in cattle however there was no significant difference in the occurrence of anti- $T$. gondii antibodies among the 2 species. Mixed infection (occurrence of Anti-Brucella spps and anti-T. gondii antibodies) was only detected in cows were 2 samples (3.4\%). There was no significant difference in occurrence of mixed infection between the samples of caprine and bovine origin $\left(\mathrm{X}^{2}=0.279, P=0.598\right)$.

\subsection{Sero-Prevalence in Relation to Animal Breed}

Both animal breeds had positive cases of Brucella spps antibody detection where $40 \%$ (6) of the samples from the local breeds, $68 \%$ (17) of those from the exotic breed and $31.6 \%$ (6) of the Cross breed samples were reported. Breed of the animal was significant risk factor highly associated with Brucella spps sero-positivity where exotic animals showed a higher sero-prevalence compared to the local and cross breeds $\left(\mathrm{X}^{2}=0.279, P=0.041\right)$. Antibodies against $T$. gondii were detected in only 2 samples (3.4\%) from animals all being exotic. However, there was no significant difference in $T$. gondii antibody sero prevalence between the different breed samples $\left(\mathrm{X}^{2}=2.815, P=0.245\right)$. Mixed infection [presence of both Brucella spps and $T$. gondii antibodies] was only detected in $3.4 \%$ (2) of exotic animals were 2 samples. There was no significant difference in occurrence of mixed infection between the samples from the different breeds $\left(\mathrm{X}^{2}=2.815, P=0.245\right)$.

\subsection{Sero-Prevalence in Relation to Region of Sample Origin}

In the present study, $60 \%$ (15) of the samples from Central Uganda and $41.2 \%$ (14) from Western Uganda were positive for Brucella spps antibodies but there was no significant difference in Brucella sero prevalence between different region samples $\left(\mathrm{X}^{2}=2.042, P=0.153\right) .4 \%$ (1) of the samples from Central Uganda and $2.9 \%$ (1) from Western Uganda were positive for antibodies against $T$. gondii. There was no significant difference in Brucella sero prevalence between different region samples $\left(\mathrm{X}^{2}=0.049, P=0.824\right)$. Mixed infection (presence of both Brucella spps and T. gondii antibodies) was only detected in $4 \%$ (1) of Central Uganda samples and $2.9 \%$ (1) of the Western Uganda samples. There was no significant difference in occurrence of mixed infection between the samples from the different regions $\left(\mathrm{X}^{2}=0.049, P=0.824\right)$.

\subsection{Sero-Prevalence in Relation to History of Reproductive Failure}

Brucella spps sero prevalence of $47.8 \%$ (22) was found in 46 animals which had 
previous history of abortion, $100 \%$ (1) in 1 animal that had previous history of still birth and 50\% (6) in 12 animals which had no previous history of any reproductive failure. There was no significant difference in occurrence of Brucella spps antibodies between animals which had different history of reproductive failure occurrence $\left(\mathrm{X}^{2}=1.070, P=0.586\right)$. T. gondii sero prevalence of $4.3 \%$ (2) was found in animals which had previous history of abortion. No T. gondii positive case was recorded for animals with history of still birth and also those which had no previous history of any reproductive failure. There was no significant difference in occurrence of $T$. gondii antibodies between animals which had different history of occurrence of failures $\left(\mathrm{X}^{2}=0.586, P=0.467\right)$. Mixed infection (presence of both Brucella spps and $T$. gondii antibodies) was only detected in $4.3 \%$ (2) of samples from animals with history of abortion. No mixed infection cases were recorded for animals with history of still birth and also those which had no previous history of any reproductive failure. Findings indicated that there was no significant difference in occurrence of mixed infection between the samples from the animals having history of any reproductive failure and no history of any reproductive failure $\left(\mathrm{X}^{2}=0.585, P=0.746\right)$.

\subsection{Sero-Prevalence in Relation to Past Frequency of Reproductive Failure}

Brucella spps sero prevalence of $70.6 \%$ (12) was found in animals which had previously aborted 4 times, followed by one abortion $43.5 \%$ (10) and no abortion history $36.8 \%$ (7). There was no significant difference in occurrence of Brucella spps antibodies between animals which had different numbers of recorded abortions $\left(\mathrm{X}^{2}=4.574, P=0.102\right)$. T. gondii sero prevalence of $5.9 \%$ (1) was found in animals which had previously aborted 4 times, followed by one abortion $4.3 \%$ [1] and no abortion history $0 \%(0)$. There was no significant difference in occurrence of $T$. gondii antibodies between animals which had different numbers of recorded abortions $\left(\mathrm{X}^{2}=1.054, P=0.590\right)$. Mixed infection [presence of both Brucella spps and T. gondii antibodies] was only detected in 5.9\% [1] of 4 times abortions samples, $4.3 \%$ (1) of the one abortion samples and $0 \%$ in the no abortion samples. However, there was no significant difference in occurrence of mixed infection between the samples having different numbers of Abortion occurrence $\left(\mathrm{X}^{2}=1.054, P=0.590\right)$. Brucella spps sero prevalence of $1.7 \%$ was found in 1 animal which had previously faced still birth. $47.6 \%$ (58) of the animals with no history of still birth were positive for Brucella spps antibodies. There was no significant difference in occurrence of Brucella spps antibodies between animals which had history or no history of still birth occurrence $\left(\mathrm{X}^{2}=\right.$ 1.052, $P=0.305)$. T. gondii sero prevalence of $3.4 \%$ (2) was found in animals with no previously history of still birth and those with occurrence of still birth had $0 \%$. There was no significant difference in occurrence of $T$. gondii antibodies between animals which had history or no history of still birth $\left(\mathrm{X}^{2}=0.36, P=\right.$ 0.850). Mixed infection (presence of both Brucella spps and T. gondii antibodies) was not detected in samples with history of still birth. 3.4\% (2) of the sam- 
ples with history of still birth had both Brucella spps and T. gondii antibodies. There was no significant difference in occurrence of mixed infection between the samples having history or no history of still birth $\left(\mathrm{X}^{2}=0.36, P=0.850\right)$.

\section{Discussion}

This study adds on to already existing data on the sero-positivity to Brucella spps, reports the existence of $T$. gondii infection and the possibility of their co-existence in Ugandan cattle and goats special emphasis on individuals with history of reproductive failure. Aspects of Brucellosis and $T$. gondii prevalence at herd level were not included. The sero-prevalence of bovine brucellosis at individual animal level was high compared to most findings got by researchers from other countries such as Al Hassan et al., 2014 (1.2\%), Aulakh et al., 2008 (20.67\%). Recent studies done in Uganda on bovine brucellosis at individual animal level by researchers Mugizi et al., 2015 (7.5\%), Miller et al., 2015 (14\%) recorded lower prevalences compared to this study. The same trend of high prevalence of Brucella spps antibodies was recorded from the samples of caprine origin. Similar research done on caprine brucellosis by researchers Rahman et al., 2015 and Mustafa et al., 1995 presented low prevalence values of $2.5 \%$ and $1.69 \%$ respectively. In the present study, majority of the samples submitted were from animals suspected to have suffered from clinical conditions associated with various reproductive failures such as abortion and still births thus sampling bias done at farm level could have played a role in the high prevalence value of Brucella spps from our study [23] [24]. Coupled to the latter, the wide distribution of brucellosis in cattle and goats sera from the private farms might be attributed to the frequent introduction of new high yielding animals into the farms forfeiting disease screening and also lack of proper herd health monitoring programmes which are mandatory in disease control [25]. The latter mentioned practices were characteristic of the different farms upon interview of the sample submitters and thus could be possible risk factors. T. gondii sero-positivity in both species was lower compared to research done by Dechicha et al., 2015in Algeria which obtained $3.92 \%$ and $13.21 \%$ rates in cattle and goats respectively. Study findings from Uganda by researchers Bisson et al., 2000 gave a prevalence $31 \%$ in domestic goats which was higher compared to ours. This could be attributed towards the low caprine sample size in our study thus diminishing the chances of targeting positive cases. In the quest for probable risk factors associated with sero-positivity, animal breed was significant risk factor highly associated with Brucella spps sero-positivity. This finding was in line with a study done by Mugizi et al., 2015 whose results pointed out that exotic breed in the Soroti study area had a higher Brucella spps sero-prevalence compared to other breeds. A significant association was also found between Brucella sero-positivity and animal species thus noted as a probable risk factor. Different researchers have marked region of origin of an animal as a possible risk factor for Brucella spps and T. gondii sero-positivity [17] [26] [27]. However, findings from our 
study showed no significant difference in Brucella spps and T. gondii sero prevalence between the 2 regions. Animal herds with history of reproductive failures such as abortion and still birth tend to have higher Brucella and T. gondii prevalences thus usually a strong association exists between sero positivity and existence of reproductive failures [23] [28]. From our findings, the insignificant association between history of reproductive failures and sero-positivity from our findings could be likely linked to occurrence of other infectious agents such as viral, fungal and other non-infectious causes of reproductive disorders in farm animals [27] [28]. In addition, probable causes could be other infectious causes of abortion like Leptospirosis that has been reported in Uganda [29] or dietary deficiencies. This gap calls for further research to determine the most significant infectious or non-infectious etiology of reproductive failures. Different researchers have studied the prevalences of 2 or more infectious causes of reproductive failures in animal herds [30] [31] [32]. However, findings on the co-existence of 2 or more infectious causes of reproductive failures in individual animals are sparse. This is the first study in Uganda to document a prevalence of 3.8\% mixed infection to Brucella spps and T. gondii in bovine samples where 2 animals which had previous occurrence of abortion were found positive. Inspite of this finding, the association between occurrence of mixed infection and history of reproductive failure was insignificant although the possibility was attained. The researchers encourage more research in this aspect basing on the baseline information. The low sample size tamed our study to small scope due to exclusion of samples that lacked adequate data on different parameters of animals and sample details. Analysis of Brucella spps and T. gondii sero prevalence in relation to age, sex was hindered by lack of proper record keeping and documentation of aspects concerning bio-data and health monitoring of animals which can be streamlined through strict policies. Brucella spps and T. gondii sero prevalence at herd level was not investigated as few animals were selected by the owners for testing thus herd related risk factors were neglected. Sample submitters lacked enough information on individual farm practices and management thus this sub-section of risk factors was not looked at.

\section{Conclusion}

The high prevalence of Brucella spps in the present study still creates a public health concern. Taming the brucellosis prevalence in animals is a step to reducing the prevalence in man due to the zoonotic nature of the pathogen and is usually associated with milk, meat and their products one of the most consumed foods among Uganda's population. From the latter, a brucellosis eradication program that has not been existent for years is emphasized. Regular animal screening and mass vaccination can be used as key strategies since they have been seen to reduce brucellosis prevalences in developed countries. At individual animal level, animal species and breed of the animal were found to be significant risk factors for Brucella sero-positivity in cows and nannies. Although the possi- 
bility of co-existence of infections causes of reproductive failure was made evident, there is still a gap regarding the subject that needs to be addressed with the view that it can be used in Animal reproductive disease diagnosis. Basing on the study, the authors believe that the results will provide more data on Brucella spps and $T$. gondii sero prevalence, infectious agents and their role in manifestation of reproductive failure.

\section{Acknowledgements}

The authors express their gratitude to Japan International Cooperation Agency Animal Disease Control (JICA-ADC) Project particularly JICA Experts Dr. Ken'ichi Sakurai (Veterinary bacteriologist), Dr. Monaya Ekgatat (Brucellosis expert) who wholeheartedly passed on their knowledge in aspects of brucellosis diagnosis by various tests and all the staff of the Central Diagnostic Laboratory.

\section{References}

[1] Bellows, D.S., Ott, S.L. and Bellows, R.A. (2002) Review: Cost of Reproductive Diseases and Conditions in Cattle. The Professional Animal Scientist, 18, 26-32. https://doi.org/10.15232/S1080-7446(15)31480-7

[2] Bisson, A., Maley, S., Rubaire-Akiiki, C.M. and Wastling, J.M. (2000) The Seroprevalence of Antibodies to Toxoplasma gondii in Domestic Goats in Uganda. Acta Tropica, 76, 33-38. https://doi.org/10.1016/S0001-706X(00)00086-3

[3] Daly, R. (2007) Control of Infectious Reproductive Disease: The Role of Biosecurity. Applied Reproductive Strategies in Beef Cattle Proceedings September, 11, 197-208.

[4] Dechicha, A. S., Bachi, F., Gharbi, I., Gourbdji, E., Baazize-Ammi, D. and Guetarni, D. (2015) Sero-Epidemiological Survey on Toxoplasmosis in Cattle, Sheep and Goats in Algeria. African Journal of Agricultural Research, 10, 2113-2119. https://doi.org/10.5897/AJAR2015.9575

[5] Yaeger, M. (1993) Cattle Abortions-Causes and Prevention. Proceedings of the Range Beef Cow Symposium XIII, Cheyenne, WY, 6-8 December 1993.

https://digitalcommons.unl.edu/rangebeefcowsymp/219/

[6] Givens, M.D. and Marley, M.S.D. (2008) Infectious Causes of Embryonic and Fetal Mortality. Theriogenology, 70, 270-285. https://doi.org/10.1016/j.theriogenology.2008.04.018

[7] Cutler, S.J., Whatmore, A.M. and Commander, N.J. (2005) Brucellosis-New Aspects of an Old Disease. Journal of Applied Microbiology, 98, 1270-1281. https://doi.org/10.1111/j.1365-2672.2005.02622.x

[8] Shareef, J.M. (2006) A Review of Serological Investigations of Brucellosis among Farm Animals and Humans in Northern Provinces of Iraq (1974-2004). Journal of Veterinary Medicine, Series B, 53, 38-40. https://doi.org/10.1111/j.1439-0450.2006.01021.x

[9] Rahman, M.S., Mithu, S., Islam, M.T., Uddin, M.J., Sarker, R.R., Sarker, M.A.S. and Akhter, L. (2013) Prevalence of Brucellosis in Black Bengal Goats in Bangladesh. Bangladesh Journal of Veterinary Medicine, 10, 51-56. https://doi.org/10.3329/bjvm.v10i1-2.15646

[10] Kaltungo, B.Y. and Musa, I.W. (2013) A Review of Some Protozoan Parasites Causing Infertility in Farm Animals. ISRN Tropical Medicine. https://doi.org/10.1155/2013/782609 
[11] Tenter, A.M., Heckeroth, A.R. and Weiss, L.M. (2000) Toxoplasma gondii: From Animals to Humans. International Journal for Parasitology, 30, 1217-1258. https://doi.org/10.1016/S0020-7519(00)00124-7

[12] Dubey, J.P. (2009) Toxoplasmosis of Animals and Humans. CRC Press, Boca Raton. https://doi.org/10.1201/9781420092370

[13] Kabagambe, E.K., Elzer, P.H., Geaghan, J.P., Opuda-Asibo, J., Scholl, D.T. and Miller, J.E. (2001) Risk Factors for Brucella Seropositivity in Goat Herds in Eastern and Western Uganda. Preventive Veterinary Medicine, 52, 91-108. https://doi.org/10.1016/S0167-5877(01)00251-3

[14] Renukaradhya, G.J., Isloor, S. and Rajasekhar, M. (2002) Epidemiology, Zoonotic Aspects, Vaccination and Control/Eradication of Brucellosis in India. Veterinary Microbiology, 90, 183-195. https://doi.org/10.1016/S0378-1135(02)00253-5

[15] Amin, K.M., Rahman, M.B., Rahman, M.S., cheol Han, J., ho Park, J. and seok Chae, J. (2005) Prevalence of Brucella Antibodies in Sera of Cows in Bangladesh. Journal of Veterinary Science, 6, 223-226.

[16] Gul, S.T. and Khan, A. (2007) Epidemiology and Epizootology of Brucellosis: A Review. Pakistan Veterinary Journal, 27, 145-151.

[17] Figueiredo, J.F., Silva, D.A., Cabral, D.D. and Mineo, J.R. (2001) Seroprevalence of Toxoplasma gondii Infection in Goats by the Indirect Haemagglutination, Immunofluorescence and Immunoenzymatic Tests in the Region of Uberlândia, Brazil. Memorias do Instituto Oswaldo Cruz, 96, 687-692. https://doi.org/10.1590/S0074-02762001000500019

[18] Jittapalapong, S., Sangvaranond, A., Pinyopanuwat, N., Chimnoi, W., Khachaeram, W., Koizumi, S. and Maruyama, S. (2005) Seroprevalence of Toxoplasma gondii Infection in Domestic Goats in Satun Province, Thailand. Veterinary Parasitology, 127, 17-22. https://doi.org/10.1016/j.vetpar.2004.08.019

[19] Hove, T., Lind, P. and Mukaratirwa, S. (2005) Seroprevalence of Toxoplasma gondii Infection in Goats and Sheep in Zimbabwe. Onderstepoort Journal of Veterinary Research, 72, 267-272. https://doi.org/10.4102/ojvr.v72i4.181

[20] Ramzan, M., Akhtar, M., Muhammad, F., Hussain, I., Hiszczyńska-Sawicka, E., Haq, A.U. and Hafeez, M.A. (2009) Seroprevalence of Toxoplasma gondii in Sheep and Goats in Rahim Yar Khan (Punjab), Pakistan. Tropical Animal Health and Production, 41, 1225-1229. https://doi.org/10.1007/s11250-009-9304-0

[21] Kamani, J., Mani, A.U. and Egwu, G.O. (2010) Seroprevalence of Toxoplasma gondii Infection in Domestic Sheep and Goats in Borno State, Nigeria. Tropical Animal Health and Production, 42, 793-797. https://doi.org/10.1007/s11250-009-9488-3

[22] Hotea, I., Dărăbuş, G., Ilie, M.S., Imre, K., Balint, A., Indre, D. and Costinar, C.P. (2010) Seroprevalence of Toxoplasma gondii Infection in Pigs Reared in Intensive System from Timis County. Lucrari stiintifice Medicina Veterinara Timisoara, 43, 68-72.

[23] Mikolon, A.B., Gardner, I.A., Hietala, S.K., de Anda, J.H., Pesta-a, E.C., Hennager, S.G. and Edmondson, A.J. (1998) Evaluation of North American Antibody Detection Tests for Diagnosis of Brucellosis in Goats. Journal of Clinical Microbiology, 36, 1716-1722.

[24] Tadeg, W.M., Gudeta, F.R., Mekonen, T.Y., Asfaw, Y.T., Birru, A.L. and Reda, A.A. (2015) Seroprevalence of Small Ruminant Brucellosis and Its Effect on Reproduction at Tellalak District of Afar Region, Ethiopia. Journal of Veterinary Medicine and Animal Health, 7, 111-116. https://doi.org/10.5897/JVMAH2014.0287 
[25] Wikipedia, Sampling Bias. http://en.wikipedia.org/wiki/Sampling_bias

[26] Mustafa, Y.S., Awan, F.N. and Hazeen, K.G. (1991) Prevalence of Brucellosis in Sheep and Goat. Group, 29, 348-351.

[27] Aulakh, H.K., Patil, P.K., Sharma, S., Kumar, H., Mahajan, V. and Sandhu, K.S. (2008) A Study on the Epidemiology of Bovine Brucellosis in Punjab (India) using Milk-ELISA. ActaVeterinaria Brno, 77, 393-399. https://doi.org/10.2754/avb200877030393

[28] Mugizi, D.R., Boqvist, S., Nasinyama, G.W., Waiswa, C., Ikwap, K., Rock, K. and Erume, J. (2015) Prevalence of and Factors Associated with Brucella Sero-Positivity in Cattle in Urban and Peri-Urban Gulu and Soroti Towns of Uganda. The Journal of Veterinary Medical Science, 77, 557-564. https://doi.org/10.1292/jvms.14-0452

[29] Al Hassan, A., Islam, M.R. and Hossain, M.M. (2014) Serological Prevalence of Brucellosis of Cattle in Selected Dairy Farms in Bangladesh. Korean Journal of Veterinary Research, 54, 239-243. https://doi.org/10.14405/kjvr.2014.54.4.239

[30] Artherstone, C., Picozzi, K. and Kalema-Zikusoka, G. (2014) Seroprevalence of Leptospira Hardjo in Cattle and African Buffalos in Southwestern Uganda. The American Journal of Tropical Medicine and Hygiene, 90, 288-290.

https://doi.org/10.4269/ajtmh.13-0466

[31] Karaca, M., Babür, C., Çelebi, B., Akkan, H.A., Tütüncü, M., Keleş, İ. and Kılıç, S. (2007) Investigation on the Seroprevalence of Toxoplasmosis, Listeriosis and Brucellosis in Goats Living in the Region of Van, Turkey. YYÜ Vet FakDerg, 18, 45-49.

[32] Adesiyun, A., Campbell, M., Rahaman, S., Bissessar, S., Stewart-Johnson, A., Dookeran, S. and Gittens-St. Hilaire, M. (2011) Frequency of Detection of Immunoglobulins of Toxoplasma gondii, Leptospira spp., and Brucella abortus in Livestock/Farm and Abattoir Workers in Trinidad. Journal of Agromedicine, 16, 200-209. https://doi.org/10.1080/1059924X.2011.581541 